allowed us to refer, where a slight operation upon the urethra was followed by an attack of this kind, the -urine upon examination was found to contain large quantities of a well-defined and handsome specimen of bacillus. A catheter had been left in the bladder after the operation in the above case, but at all events, the concurrence of the attack of chill and fever, with the undoubted presence of micro-organisms in the urine, is suggestive.

Internal urethrotomy being unsuited to strictures situated posterior to the bulb by reason of uncontrollable hæmorrhage sometimes occurring and working back into the bladder, they are if of small size well treated by divulsion, although for such strictures external perineal urethrotomy is now being regarded with more favor than formerly. In the latter operation bleeding is under control, and the operation itself dangerous to life only in cases where any interference is dangerous. This operation owes its comparatively high death-rate to the fact that it has usually been done only in the desperate cases of tight stricture of long standing. Moreover, deep strictures, if of large calibre, are often particularly amenable to treatment by gradual dilatation. There is evidence, however, to show that many of them are spectres conjured up by the presence of anterior strictures of greater or less calibre, and thus their relative numerical importance becomes diminished. In every instance all anterior constrictions should be thoroughly removed before attention be given to the deeper ones, which may then vanish as if by magic. Our own limited experience also, as far as it goes, confirms the statement that by far the largest number of strictures are situated in the anterior portion of the urethra within four inches of the meatus; in other words, that deep strictures are comparatively uncommon. The cases which we have collected, so far as they go, illustrate how unnecessary it is to leave a catheter in the bladder after operation for stricture. Whether we would have had a smaller proportion of chills if we had done so is of course a mere matter of speculation, but the retention of a catheter in the urethra does not prevent the contact of urine with the wounded surfaces. If this be so it is worse than useless by the mechanical irritation of its presence, tending to cause urethritis and affording to micro-organisms a direct route to the bladder.

'There is no one kind of treatment which is equally adapted to all cases, and a fair comparison of the different methods of treatment is only to be attained by taking into consideration the character of the cases as well as the method of operation. Like every other diseased condition stricture is more amenable to treatment of any sort when of recent formation, or generally speaking of large calibre, but in any case it is probable that complete division of the stricture tissue by means of the kuife offers the best chance of a permanent cure. Sir Henry Thompson says in the Jacksonian prize essay upon Stricture, "I am disposed to think at present that a well-performed internal urethrotomy is more enduring in its results than any other operative procedure."

Treatment is modified in each instance by many attending circumstances, by the physical condition and idiosyncrasies of the patient, by his mental attitude towards the knife, and by the character, number, and situation of the strictures present.

We wish to be considered as reasonable advocates of internal urethrotomy as done by Otis's method, - an operation worthy of more attention than has been given to it in Boston, an operation not proper in all cases, nor always successful, but one which, when rightly done in suitable cases, is the one of all others which, without danger to the patient, brings to him the most speedy relief and the best chance of a radical cure.

In concluding, we wish to express our thanks to the Sister Superior of the Carney Hospital for the excellent care and attention which have been bestowed upon our patients, and to Drs. Devine and Hall for their kind and intelligent management of the cases while under their care.

\section{REPORT OF A CASE OF MURDER.?}

by a. elliot paine, M. D., Medical examiner.

ON the morning of September 26, 1879, I was called to Bridgewater to view the body of a man found dead in his house. I drove down, and, with one of the selectmen of the town, went to the house and found the dead body of Justin L. Gunn lying on the floor of a small bedroom, about eight by ten feet. The body was face downwards, with shirt and drawers on, in a mass of dried blood. There was no carpet on the floor; the only furniture in the room being an old-fashioned corded bed. There was one window on the side of the room, near the foot of the bed, and a door just at the head of the bed; there was another door at the opposite side of the room. The bed was in the corner of the room, so that it came near the door; the foot of the bed was drawn away from the wall about twelve inches; the bedclothes were thrown backwards, and the front part of the bed was depressed, showing that some one had lain there; the pillow and depressed portion were saturated with blood; the head-board and the walls, ceiling, and door, were spattered with blood. On investigation I learned that the deceased and his son had been living in the place a few months, carrying on a farm; that both had their sprees, and quarreled often. 'The son had remarked he would "fix the old man some day." The neighbors had last seen the murdered man on the evening of the 24th of September, about ten o'clock. He was then alone in the house. Nothing was seen of the father and son on the 255th, and it was supposed that they had gone away. On the morning of the 26 th the neighbors noticed the cows had not been tied up, and were uneasy and noisy. The neighbors then looked around the premises; found the doors fastened. On looking into the bedroom window they saw the blood on the wall, and gave the alarm. In a sink in the room adjoining the bedroom, used as sitting and dining room, there was a small cabinet in which papers, etc., were kept. It had been broken open, and near it was a large screw-driver with blood on it. I did not examine the body at my first visit, but locked the house, and left it in charge of a neighbor, and sent a telegram to the district attorney asking for detectives. I also learned that the son was seen on his way to the railroad station (about three miles from the place) on the morning of the 25th of September.

In the afternoon of the day of the view, after getting authority to make an autopsy, I went to the house accompanied by the district attorney, and with the

1 Read before the Massachusetts Medico-Legal Society, February 7,1883 . 
assistance of Drs. Pratt and Sawyer I made a thorough examination.

On the pillow were a few small pieces of bone and brain substance. On the mattress, between the headboard and pillow, was a piece of bone about half an inch wide and an inch long. Hanging to the outer head-post was a pair of trousers (or overalls); one leg was quite bloody, and sticking to the cloth was a piece of bone about one inch wide and an inch and a half long. The head of the body was just under the edge of the bed, with the legs extending to the wall; one leg was drawn partly up, and one arm was under the body. I turned the body over, and found the nose flattened. We then removed the body to another room, and made the autopsy with results as follows:-

External appearances. The head and upper part of body were covered with dry blood. There was a large wound on the right side of the head, above and in front of the right ear, measuring three and three quarters by two and a quarter inches; from this wound brain substance was protruding. Another wound in the right frontal region measured two inches in length, and extended across the forehead. There was also a triangular wound, three fourths of an inch long and one fourth of an inch wide, just above the right eyebrow. No other wounds were found on the body. Rigor mortis was well marked, as was the cadaveric lividity on the front of body.

Internal appearances. On turning back the scalp a blood clot was found covering the whole right side of the head. Under the wounds were found fractures of the skull corresponding with the wounds. A number of loose pieces of bone were removed, one piece extending from lower part of large wound downwards, and in front of the right ear, measuring four and au eighth inches by one and a half inches. A fracture of the skull was found extending from the upper part of the large wound on the right side of the head towards the left ear, in a triangular shape, three and a half inches. On removing the skull the membranes were found destroyed under the large wound, and the whole right hemisphere was covered with a clot of blood. 'The larger part of the right hemisphere was lacerated. The rest of the brain was normal.

'There were old pleuritic adhesions of the right lung in its posterior portion, and of the left at the apex; otherwise the lungs were normal, as were all other organs.

The cause of the death was thus determined to be a compound comminuted fracture of the skull, the result of violence. It was our opinion that the man was killed while lying on his left side in the bed; that he must have received a number of blows at the large wound to produce such a destruction, and that the blows must have been given just as the assailant came through the door of the bedroom, and in all probability were made while the victim was asleep, there being no signs of a tussle.

Some three weeks after this the son was arrested, when he confessed that he killed his father. He said that on the night of the 24th of September he (the son) came home about half past ten or eleven o'clock. His father began scolding about some work; from words they came to blows; his father struck him with the screw-driver, and then went into the bedroom. The blow so angered him (the son) that he went to a back room and got a hatchet, and going into the bedroom, as his father was sitting on the edge of the bed, he concealed the hatchet, and as he passed he struck his father on the head twice or three times. The father fell over on the bed, and he did not strike him again. He saw what he had done, and threw the weapon into a pile of wood (where it was found by the officer), and broke open the cabinet expecting to find money. $\mathrm{He}$ then changed his clothes, taking about half an hour. He then left the house and went into the barn, where he slept over night. He drove the cows to pasture in the morning, and took the cars to Boston.

The case was tried at Plymouth in the spring of 1880. The son testified to the same facts as he had previously confessed. On cross-examination he said that his father was on the bed groaning when he left the louse; that he did not put him on the floor. The medical expert for the defense said that the man could have lived as long as was testified, and had voluntary motion enough to throw himself out of bed. It is to be remembered that where the body lay in bed it was several inches lower than the edge, and the body was found with the head under the edge of the bed, and the trunk and feet away from it.

The government attorneys claimed that the man was killed in bed; that before leaving the house the son dragged him out of bed, and drew the foot of the bed out from the wall so that the body could not be seen from the windows, either at the foot of the bed or through one in the dining room opposite the door in the bedroom (a table being in the way). The son was found guilty of murder in the second degree, and is now at Concord. He said, when sentence was passed, he preferred death, and as the officer left him a few minutes on the morning of his leaving the jail he cut his throat, making five cuts; being in too great haste he did a poor job.

\section{REPORT ON LAWS REGULATING THE PRAC- TICE OF MEDICINE IN THE UNITED STATES AND CANADA. ${ }^{1}$}

BY RICHARD J. DUNGLISON, M. D., AND HENRY O. MARCY, M. D.

THe progress made in the legislative restriction of medical practice in the United States since your committee was appointed, three years ago, to report upon the subject, has been both notable and salutary. At that time the propriety of establishing such laws was under active discussion, and weak enactments, temporizing in character and but partially effective in their action, were evoked from tardy and timorous legislators in several of the States of this country, as compromises between a sense of the necessity of doing something to protect the health of their constituents and a consciousness that the practitioners and supporters of quackery and of irregular methods of medical treatment were among the influential voters whose active opposition might jeopardize their reëlection. It was also found to be impossible, in a few of the States, to establish regulations for the practice of medicine which would be shaped to the wishes, principles, or prejudices of those members of the legislatures who believed that they themselves were occasionally benefited by prescriptions that were not wholly scientific in their character, or by remedies that had acquired their reputation by extensive advertising of their supposed merits and efficacy. The legislation of the last year or two, however, seems tending to greater stringency, and to

1 Report of a Committee read before the American Academy of Medicine at New York, October 10, 1883. 